\title{
Content and temporal structure of autobiographical knowledge: Remembering twenty-five seasons at the Metropolitan Opera
}

\author{
JEROME R. SEHULSTER \\ University of Connecticut, Stamford, Connecticut
}

\begin{abstract}
Three experiments were designed to explore the structure and content of a well-defined subset of very long-term autobiographical memory. In Experiment 1, the author free-recalled in a single session details about the dates and casting of 284 opera performances seen at the Metropolitan Opera over a period of 25 seasons. Recall accuracy was measured by comparing the recall with the programs for each performance. Primacy and recency effects were prominent in recall of both temporal and casting details. Also, recall of performances was superior if the performances were included in the sequential structures of seasons in memory. Experiments 2 and 3 were designed to examine the effect of an opera performance's relative importance (or intensity) and opportunities for rehearsal of an opera performance on the author's free recall of the performance. In Experiment 2, importance/rehearsal opportunity was estimated from nine sources, including recordings, telecasts, tapes, and photograph books. In Experiment 3, the set of opera performances was rated and ranked by four opera experts on the dimension of intensity or importance of each performance. In both experiments, importance/rehearsal opportunity was related to superior recall of casting but not to recall of temporal details. Results suggest that detailed temporal structure in autobiographical memory is lost over time, whereas contents may be updated through various forms of rehearsal.
\end{abstract}

The research reported here is primarily a descriptive investigation of the free recall of a vast, temporally structured, and well-maintained subset of one person's very long-term autobiographical memory. Three questions are addressed: First, what form does the exhaustive recall of a large serial list of autobiographical facts take? Second, what is the impact of higher order temporal chunking on the organization and recall of this list of autobiographical facts? And third, what factors affect the storage and maintenance of this subset of autobiographical facts?

The temporal sequence of events and actions as we experience them provides a natural serial order for our memories. We know the general sequence of events in our lives (Fuhrman \& Wyer, 1988; Robinson, 1986), as well as the sequential orders of scripted actions (Barsalou \& Sewell, 1985). Though we can deconstruct the temporal organization of these memories to meet various and

\footnotetext{
The author wishes to thank Elise A. Sehulster, Robert G. Hand, Jeremy A. Richard, Jean E. Lenahan, and Richard G. Schuller for their participation in Experiment 3. Deep appreciation is extended to Maria F. Chumas for her rendering of Figure 1, and to Elise A. Sehulster for her typing of the Tables. Many of the ideas in this paper were discussed with Craig R. Barclay, William F. Brewer, Darryl Bruce, and David C. Rubin. I am especially grateful for their insights and encouragement. To the anonymous reviewer, who knows of the "heavenly length" of Schubert's Great C Major Symphony, and to Robert W. Proctor, who knows of the not so heavenly length of previous drafts of this manuscript, my thanks for their many valuable suggestions. Requests for reprints should be sent to Jerome R. Sehulster, Department of Psychology, University of Connecticut, Stamford, CT 06903.
}

sundry retrieval demands, most adults retain temporal structures for a lifetime.

Here the focus is on the recall of a serial list of autobiographical facts extending back 25 years into the past. On reflection, we find that natural serial lists abound in our mnemonic lives: we can recall the more personal lists of school teachers or lovers we have had, houses or apartments we have lived in, conferences we have attended, publications, and so on. Brewer (1986) classifies these as autobiographical facts or personal memories, depending on the amount of imagery accompanying recall, and distinguishes them from memories of more schematic or scripted actions, such as eating in a restaurant or going to the dentist (Schank \& Abelson, 1977).

We can also recall more public lists of events ordered serially in time: news events, presidents and vice presidents, Super Bowls, Academy Award Winners, and so on. Public events always occur in the context of our personal experiences. Thus, understandably, we find that personal and public lists interface in memory. Subjects draw freely from both in the ordering and dating of public events (N. R. Brown, Rips, \& Shevell, 1985; Friedman $\&$ Wilkins, 1985) and personal events (Thompson, Skowronski, \& Lee, 1988).

In many studies (see Linton, 1975; Wagenaar, 1986), the corpus of autobiographical facts has been sampled through the use of cues; an exhaustive serial recall hasnot been attempted. Small wonder; the total recall of several years worth of daily events would be a formidable task. To study the temporal organization of autobio- 
graphical facts, a list is needed that spans a long period of time and yet does not contain an overwhelming number of entries.

One such list can be found in my own past: The spring of 1987 brought to a close my 25th season as a patron of the Metropolitan Opera in New York City. I have, over the past 25 seasons, assembled an active, extensive, and clearly defined subset of facts and personal memories in autobiographical memory.

From a methodological standpoint, many conditions favored the use of this subset in an exhaustive free recall experiment. First, its units are neatly bounded experiences: a person is either at the opera or not. Second, the temporal structure is clearly delineated: each new unit was added to the list in a unique temporal position defined by the date of its performance. The amount of time elapsed between each event and the present is fixed by this date, making it possible to assess passage of time as a critical variable. And the endpoints of the set are clearly defined: the beginning of the list is my first opera at the Metropolitan in the 1962-1963 season, and the end of the list is the last opera of 1986-1987.

Third, each opera on the list is, in effect, a category for various performance details: the opera cast, conductor, production, season, performance date, and so on. Fourth, and most important, the accuracy of my recall of these details can be checked against an independent record of the event. I have the program for every performance I have seen. However, fifth, I have not had, over these 25 years, any opportunities to review these programs and relearn the exact details of the performances. All the programs are packed in boxes and stored. Here, as in most everyday experiences, each event occurred and was duly recorded in memory, but no formal review or rehearsal of the exact details of the experience was possible.

Sixth, the memory set is sufficiently large but not overwhelming. Before embarking on the recall task, I estimated that the set consisted of about 300 performances at the Metropolitan Opera. And seventh, the storage of the information tapped here was completely within the framework of everyday remembrance. Unlike Wagenaar (1986) or Linton (1975), I did not intentionally store details of opera performances for subsequent recall in a formal investigation of autobiographical memory.

What is the impact of higher order temporal chunking on the organization and recall of this list of autobiographical facts? The time line of our experience can be punctuated into larger, meaningful contexts of events (Fuhrman \& Wyer, 1988; Robinson, 1986). Neisser $(1982,1986)$ and Robinson (1986) argue that we use actions to define the passage of time, and that smaller, more immediate actions or events (grading papers, for instance) are nested in the context of larger, more expansive actions (teaching a course in a particular semester). Though going to the opera is a unique act, it occurs within a larger temporal chunk: the opera season. And opera season, in turn, can be chunked into larger temporal units of, say, career, dwellings, or relationships. Robinson calls the cognitive representations of these time chunks temporal reference systems, and he supports their existence by showing that autobiographical recall of school-related events clusters around the time boundaries of the school year. Is such evidence found in the recall of a very long-term list of autobiographical facts? Experiment 1 deals with this question as well as with general questions about the form of free recall.

In Experiments 2 and 3, factors that affect the storage and maintenance of this subset of autobiographical facts are explored. Several variables have been isolated that seem to affect the storage and retrieval of events from autobiographical memory. Rubin and Kozin (1984) and R. Brown and Kulik (1977) have suggested that consequential and significant, emotional, or unexpected events are vivid in memory and remembered well. Events extremely pleasant or unpleasant are recalled better than events of neutral affect; temporal details are more likely to be stored in memory for pleasant events than for unpleasant events (Thompson, 1985). In addition, actions that are inconsistent with script expectations are often remembered better than actions that are consistent (Nakamura \& Graesser, 1985). Perhaps, as suggested by Hashtroudi, Mutter, Cole, and Green (1984), extra attention is paid to the unexpected.

Within the generally pleasant experience of attending the opera, there are wide variations in the artistic and emotional intensity of performances. Are more intense experiences remembered better than less intense experiences? In Experiment 2, it is reasoned that the most intense operatic events are more likely recorded for posterity on recordings, in videos, and in photographs. In the spirit of Simonton's (1977) citation criterion, where the aesthetic importance of a composer's compositions was rated according to the number of sources (out of 15) in which each piece was cited, the intensity of an operatic experience was estimated by the degree to which cast members and conductor appeared in the various media. In Experiment 3, five experts, well endowed with a general knowledge of opera and of Metropolitan Opera performances in particular, used cast and conductor information to rate each performance on my list for the degree to which the performance was intense and memorable. If more intense performances are indeed more memorable, then these performances should be better remembered in the free recall task.

Rubin and Kozin (1984) point out, however, that vivid memories are also more likely to be retrieved and rehearsed in conversation over the years, especially if the event recalled is socially or personally significant. For the opera patron, the most memorable opera performances are also the ones most often remembered, discussed, and debated. In Experiment 3, then, the ratings of performance intensity can also reflect the degree to which the details of performance come up in conversation and, thus, are rehearsed. Experiment 2, also, confounds a rating of the intensity or memorability of a performance with rehearsal, in that listening to a recording, watching a video, 
or leafing through a photograph book provides an opportunity to retrieve and maintain autobiographical memories, just as reviewing one's yearbook or attending a high school reunion provides an opportunity to rehearse very long-term memories of former classmates (Bahrick, Bahrick, \& Wittlinger, 1975). Confounds such as these are unavoidable in a study of very long-term everyday memory such as this.

\section{EXPERIMENT 1}

\begin{abstract}
Method
Materials. A 35-page booklet was constructed from sheets of computer paper. Each of the 25 seasons, starting with the 1986-1987 season and ending with the 1962-1963 season, was given a separate sheet with a clear heading. Six pages preceded these for notes, and 4 pages followed for the isolated recall of performances, bits of information, and so on.

Definition of the subset. I limited recall to Metropolitan Opera performances. This rule neatly circumscribed the memory subset: It included all performances by the Metropolitan Opera company at the Metropolitan Opera Houses (both the old Metropolitan Opera House on 39th Street and Broadway and the new Metropolitan Opera House in Lincoln Center), and it eliminated opera performances by other companies (e.g., the New York City Opera or Connecticut Grand Opera) or performances given by other companies at the Metropolitan Opera House (e.g., the Bolshoi Opera). ${ }^{1}$

The decision to limit the target memory set to Metropolitan Opera performances and to exclude the performances of the other companies was based on the easy availability of documentation and ancillary information (books, recordings, and so on) used in Experiment 2.

Recall was restricted to the singers in the major roles of the opera, and hit-or-miss guessing was avoided.

Procedure. Each recalled performance was recorded in ink with as many performance details of cast and time structure as possible. Each recall was given a sequence number in red, indicating its place in the output sequence. Any insertions, last minute recalls, or sudden flashes of memory were also given sequence numbers. In addition, the entire recall session was given a running commentary and recorded on audio tape. The recall session began on the morning of July 15,1987 , and continued for $7.5 \mathrm{~h}$ until the late afternoon. I took four breaks of about $10 \mathrm{~min}$.
\end{abstract}

\section{Results}

Scoring. A master scoring sheet was prepared. Each season was given a separate page; details from performances were recorded on the appropriate season page. Complete temporal information (day, date, and matinee/evening) and the names of the conductor and the artists singing the major roles for each performance were taken from my original Metropolitan Opera programs. ${ }^{2}$

I witnessed a total of 282 performances (and 2 dress rehearsals) by the Metropolitan Opera Company over the course of 25 seasons. Each of the 284 performances was entered into a data file as a separate data point in chronological order from the first opera (Fledermaus, on April 13, 1963) to the last (Parsifal, on April 17, 1987). The exact date of the opera was recorded for identification purposes. Each file entry reflects a real, documented event and will be referred to as a real performance-in contrast to my remembered version of the event, which will be referred to as a recalled performance.

Each real performance entry was assigned 1 or 0 depending on the presence or absence of certain characteristics; each characteristic thus became a dummy coded qualitative variable. For instance, was the opera sung in German? Was it sung in Italian, in French, in Russian, in English? Was it performed on a Monday? (or on a Tuesday, Wednesday, and so on?) Was it an evening performance or a matinee? Was it a new production of the opera?

Several ordinal variables were constructed for each real performance entry. Each performance was assigned an overall chronological sequence number (from 1 to 284) and a within-season chronological sequence number (from 1 to the number of performances in the season). In addition, a number was given to each performance, reflecting the cumulative count of performances of that opera.

The information from the recall booklet was then compared with the master scoring sheet. Each of the operas in the recall booklet (a recalled performance) was matched to one of the 284 performances in the data file (a real performance). A performance was considered remembered if it matched a real performance entry on the master list; a performance was considered remembered within a season if the particulars of the performance were written on the page for that season in the recall booklet. If the performance actually occurred in a different season, the real performance entry was located in the data file, the season error recorded, and further scoring continued. There were very few ambiguities regarding the accurate matching of a recalled performance with its real performance counterpart. These ambiguities were easily resolved through referring to other possible matches (cast, for instance) for the real performance in question. If there was no recalled counterpart to a real performance, then a total omission was noted.

Once each recalled performance was matched with a corresponding real performance, the final scoring of recall of temporal details, cast, and conductor commenced. Recall data entries were dummy coded 1 or 0 for "yes" or "no" responses to the following questions:

1. Did I recall the opera? (i.e., could a recalled performance be matched with a real performance entry?)

2. Did I recall the correct season in which the real performance took place?

3. Did I recall the correct month of the real performance?

4. Did I recall the correct day of the real performance?

5 . Did I recall the correct date of the real performance?

6. Did I recall whether the performance was an evening or a matinee performance?

In most cases, a 0 coding for one of these six temporal structure questions represented an omission of the correct information. In other cases, however, I attempted to 
recall temporal information of which I was unsure or of which I was certain but, as it turned out, wrong. Four error questions, dummy coded 1 or 0 for a "yes" or "no" response, were constructed:

1. Did I make an overt error in recall of the season of the real performance?

2. Did I make an overt error in recalling the month of the real performance?

3. Did I make an overt error in recalling the day of the real performance?

4. Did I make an overt error in recalling the date of the real performance?

The scores of the five correct temporal recall questions were summed to create a quantitative variable called temporal recall; the scores of the four temporal recall error questions were summed to create a quantitative variable called temporal error.

Scoring the cast and conductor followed the same procedure. Six cast-recall questions were answered with a 1 or a 0 response:

1. Did I recall one cast member correctly?

2. Did I recall a second cast member correctly?

There were six cast-recall questions. A seventh recall question was reserved for the conductor of the performance:

\section{Did I recall the conductor correctly?}

As with the temporal recall questions, in most cases a 0 coding for one of these seven cast-recall questions represented an omission of the correct information. In other cases, however, I attempted to recall a cast member of whom I was unsure or of whom I was certain but, as it turned out, mistaken. Three error questions, given a 1 or a 0 response, were constructed:

1. Did I make an error in the recall of one cast member?

2. Did I make an error in the recall of a second cast member?

3. Did I make an error in the recall of the conductor of the performance?

Only two cast-member error questions were needed, because there were never more than two such errors in one performance.

The scores from the seven correct cast-recall questions were summed to create a quantitative variable called casting recall; the scores from the three cast-recall error questions were summed to create a quantitative variable called casting error.

In sum, the four quantitative variables reflecting my recall are temporal recall, temporal error, casting recall, and casting error. Two total recall variables were formed by summing corresponding temporal and cast variables: Total correct recall equalled the combination of temporal recall and casting recall, and total error equalled the combination of temporal error and casting error.
Performance counts. Two hundred seventy-eight performances were recalled out of the set of 284 real performances. Six performances were completely omitted; no performances were recalled that could not be unambiguously matched with a real performance (i.e., I never "remembered" a performance that I did not attend). Further details of temporal recall are presented in Table 1.

Temporal recall is less and less complete as the information required to locate a performance in the temporal structure becomes more and more specific. Whereas I was correct in placing opera performances in season in $88.7 \%$ of the cases, I was able to recall correctly the exact date in only $7.4 \%$ of the cases.

At least one cast member was correctly recalled for 274 of the performances. A total of six cast members were recalled for 33 performances, five for 49 performances, four for 76 performances, three for 66 performances, only two for 35 performances, and only one cast member was recalled for 15 performances. As for errors in cast recall, two were made in the recall of 16 performances, and only 1 error was made in another 40 performances. The conductor of the performance was correctly recalled 206 times and incorrectly recalled only 13 times. The conductor was not mentioned for the remaining 65 times.

Other distribution details are presented in Table 2.

Correct recall. The mean correct recall of temporal features of the 284 performances was 3.12 (out of a possible 5); the mean correct recall of casting features was 4.35 (out of a possible 7). Correct recall of temporal features correlated significantly with correct recall of casting features $[r(200)=.376, p<.01]^{3}$

Of both types of overt recall error (temporal error and casting error), the mode was zero errors. As stated above, omission was the most frequent type of incorrect recall. Not surprisingly, recall errors of temporal features were negatively correlated with correct recall of temporal features of performances $[r(200)=-.368, p<.01]$, and recall errors of casting were negatively correlated with correct recall of casting $[r(200)=-.286, p<.01]$. Of interest, however, was that neither of the two types of error was correlated to the opposing correct recalls $(r=.044 ; r=.008)$, nor were the two related to each other $(r=.042)$.

Did the day of the real performance affect my recall of aspects of that performance? Yes, clearly so: I was able to recall the actual day of the performance when the performance had been on a Saturday $[r(200)=.271$, $p<.01]$ and when the performance had been a matinee

Table 1

Frequency Distribution of Correct Recall, Overt Errors, and Omissions

\begin{tabular}{lcccc}
\hline $\begin{array}{l}\text { Performance } \\
\text { Detail }\end{array}$ & $\begin{array}{c}\text { Correctly } \\
\text { Recalled }\end{array}$ & $\begin{array}{c}\text { Incorrectly } \\
\text { Recalled }\end{array}$ & Omitted & Total \\
\hline Performance & 278 & 0 & 6 & 284 \\
Season & 252 & 23 & 9 & 284 \\
Month & 199 & 20 & 65 & 284 \\
Day & 98 & 2 & 184 & 284 \\
Date & 71 & 21 & 192 & 284 \\
\hline
\end{tabular}


Table 2

Frequency Distribution of Performances by Language, Day of the Week, and Production Status

\begin{tabular}{lllllll}
\hline German & Italian & French & Russian & English & & \\
111 & 99 & 28 & 15 & 31 & & \\
Monday & Tuesday & Wednesday & Thursday & Friday & Saturday & Sunday \\
29 & 43 & 31 & 58 & 46 & 75 & 2 \\
New Production: 83 & & & & & \\
Revivals: 201 & & & & & \\
\hline
\end{tabular}

$[r(200)=-.191, p<.01]$. Recall of the day of the week of the performance was less likely if the opera had been on a Wednesday $[r(200)=-.159, p<.05]$.

More cast information was recalled if a performance had been on a Monday $[r(200)=.154, p<.05]$ or if the performance had been a matinee $[r(200)=-.176$, $p<.05]$. Also, more casting information was recalled if the performance had been a new production $[r(200)=$ $.246, p<.01]$. A performance's status as a new production did not aid recall of overall temporal features of the performance $(r=.027)$, though it did aid my recall for the month of the performance somewhat $[r(200)=.150$, $p<.05]$

An analysis of recall as a function of the language of the performance shows some marked differences in the pattern of correlation. If the opera was in German, I was more likely to recall the conductor $[r(200)=.234$, $p<.01]$, as well as up to five cast members $[r(200)=$ $.206, p<.01$ ]. If the opera was in Italian, however, I was less likely to recall the conductor $[r(200)=-.196$, $p<.01]$, more likely to make an overt error on recall of the conductor $[r(200)=.158, p<.05]$, and less likely to recall up to five cast members of the opera $[r(200)=$ $-.205, p<.01]$. No interesting patterns were observed for the operas in Russian, French, or English.

Serial position analysis. Traditional analyses of list learning data focus on such stable phenomena as the primacy and recency effects. Are these effects found in a long serial list generated from autobiographical memory? A cursory look at the pattern of correct recall for casting and temporal details revealed the familiar serial position curve. Given this shape, a simple linear regression analysis provides an inadequate description. The best solution to the problem was to analyze these data with polynomial regression. The rather flattened, parabolic shape of the serial position curve suggested that a quadratic regression equation would suffice to describe these data. The function

$y^{\prime}=P_{1}+P_{3}(X)+P_{5}(X)^{2} / 1.000+P_{2}(X)+P_{4}(X)^{2}$

was selected from BMDP3R, one of the BMDP polynomial regression programs. Real performance order from 1 to 284 and the number of correct recall were used as quantitative variables. Since the ranges of scores for the recall variables were only 5 and 7 units in contrast to the range of the values for real performance order of
284 units, a logarithmic transformation was performed on the values for real performance order.

Significant increases in variance accounted for beyond linear regression were found in all three analyses of the relationship between correct recall and serial position. Whereas the strength of the relationship $\left(\omega^{2}\right)$ between serial position and correct recall of casting was .0030 with linear regression, the quadratic regression increased the strength of the relationship $\left(\omega^{2}\right)$ to .1121 . The analysis of variance for correct recall of casting shows that the quadratic trend was significant, while the linear trend was not $\left[F_{\text {lin }}(1,279)=.937\right.$, n.s.; $F_{\text {quad }}(3,279)=11.425$, $p<.01]$.

Similarly, the strength of the relationship between correct recall of temporal features and serial position was .0117 with linear regression; the strength of association was increased to .1969 with quadratic regression $\left[F_{\text {lin }}(1,279)=4.067, p<.05 ; F_{\text {quad }}(3,279)=21.450\right.$, $p<.01]$.

Finally, the analysis of the overall correct recall showed an increase in strength of association from the linear of .0086 to the quadratic of $.1860\left[F_{\mathrm{lin}}(1,279)=2.933\right.$, n.s.; $\left.F_{\text {quad }}(3,279)=20.277, p<.01\right]$.

The residuals from the three polynomial analyses were entered into the data files for later use.

Analysis of temporal reference systems. Robinson (1986) argued that domains of action in a lifetime can function as temporal reference points in autobiographical memory. The opera season separates each functional year into two clearly defined segments, and each season may be considered a temporal category into which the members of that category (performance, cast, and specific temporal details, plus other experiences) are stored. But, as with every other life, my life has several other temporal reference systems, defined by other domains of action, which overlap the system of opera seasons. Do any of these more personally meaningful systems provide a more useful way to segment the list of performances than some less personal segmentation?

One temporal reference system is school years grouped according to the stages of my education and academic career. It yielded five large temporal groups: seasons during my high school years (3 seasons/18 performances); seasons during college (4 seasons/28 performances); seasons during graduate school (6 seasons/52 performances); seasons as assistant professor at the University of Con- 
Table 3

Mean Correct Recall for Temporal Details and Casting for Five Meaningful Divisions of Time Contrasted with Five Equal Divisions

\begin{tabular}{lccccc}
\hline & \multicolumn{5}{c}{ Stages of Academic Career } \\
\cline { 2 - 5 } \multicolumn{1}{c}{$\begin{array}{c}\text { Mean Correct } \\
\text { Recall }\end{array}$} & High School & College & Graduate & $\begin{array}{c}\text { Assistant } \\
\text { Professor }\end{array}$ & Tenured \\
\hline Temporal & 3.944 & 3.321 & 3.308 & 2.606 & 3.345 \\
Casting & 5.167 & 4.714 & 4.212 & 3.606 & 5.000 \\
$N$ Performances & 18 & 28 & 52 & 99 & 87 \\
Duration in Years & 3 & 4 & 6 & 6 & 6
\end{tabular}

\begin{tabular}{lccccc} 
& \multicolumn{6}{c}{ Seasons } \\
\cline { 2 - 6 } & $\begin{array}{c}1962-1963 \\
\text { to }\end{array}$ & $\begin{array}{c}1967-1968 \\
\text { to } \\
1966-1967\end{array}$ & $\begin{array}{c}1972-1973-1972 \\
\text { to }\end{array}$ & $\begin{array}{c}1977-1978 \\
\text { to }\end{array}$ & $\begin{array}{c}1982-1983 \\
\text { to }\end{array}$ \\
Temporal & 3.806 & 3.000 & 2.714 & 2.840 & 3.440 \\
Casting & 5.111 & 4.111 & 3.643 & 4.099 & 4.907 \\
$N$ Performances & 36 & 36 & 56 & 81 & 75 \\
Duration in Years & 5 & 5 & 5 & 5 & 5 \\
\hline
\end{tabular}

necticut (6 seasons/99 performances); and, finally, seasons after tenure ( 6 seasons $/ 87$ performances).

In contrast, I took the less personal and more obvious division of 25 seasons into five groups of 5 seasons each. This division yielded different but also unequal numbers of performances ( 36 performances during the first 5 seasons; 36 during the second $5 ; 56,81$, and 75 performances in the last three divisions, respectively). For this grouping, both measures of correct recall (temporal and casting) show the classic primacy and recency effects (see Table 3). The differences between means were significant $[F \mathrm{~s}(4,279)=6.95$ and 7.24 , respectively, $p<.01]$. Given the serial position analysis, it should come as no surprise that the primacy/recency effect is observed with this analysis.

The important question is whether the other, more personal grouping system will yield a more dramatic serial position effect than that yielded by the more objective grouping. As expected, a significant primacy/recency effect is observed when recall is grouped according to the five stages in my academic career [see Table $3 ; F(4,279)$ $=7.91$ for recall of temporal features and 10.20 for recall of casting, $p<.01$ ]. The strength of the relationship $\left(\omega^{2}\right)$ for this analysis by stages of career was compared with the strength of relationship in the earlier analysis of five equal divisions of time. The $\omega^{2}$ for recall of temporal features in this analysis was .1018 as compared to .0906 in the earlier analysis; the strength for recall of casting was .1285 this time and .0940 earlier.
Does the use of a personally meaningful division of seasons reflect a significant increase in the strength of association over that found when recall is grouped by the more objective equal divisions of seasons? The question is analogous to asking whether adding a second predictor variable increases $R^{2}$ significantly. $\omega^{2}$ of the analysis of recall with seasons divided into equal groups was taken as the equivalent of $R^{2}$ with one variable in the equation. $F$ for the increase in $R^{2}$ was calculated by treating the greater $\omega^{2}$ as the new $R^{2}$ obtained by adding a second predictor variable to the equation (Kerlinger \& Pedhazur, 1973). Both $F$ s were statistically significant [for correct recall of temporal information, $F(1,281)=3.948$, $p<.05$; for correct recall of casting, $F(1,281)=11.111$, $p<.01]$, suggesting that a meaningful division of seasons does, in fact, provide a real gain in explanatory power over the grouping of seasons by equal divisions of seasons.

Error analysis and temporal reference systems. There were 6 performances completely omitted from recall out of the 284: all 6 of these performances occurred in the fourth division of my academic career, here labeled assistant professor. The correct season of a performance was recalled, on the average, $95.3 \%$ of the time for the other four time divisions, but only $78.8 \%$ of the time for performances during the fourth division. Sixty-six percent of the season recall failures during the fourth division were overt errors. A similar pattern is found when the recall of month and day is examined.

Table 4

Frequency Distribution of Correct Recall,

Overt Errors, and Omissions in the Recall of the Exact

Date of Performances for Five Meaningful Divisions of Time

\begin{tabular}{lcccccc}
\hline & \multicolumn{6}{c}{ Stages of Academic Career } \\
\cline { 2 - 7 } & High School & College & Graduate & $\begin{array}{c}\text { Assistant } \\
\text { Professor }\end{array}$ & Tenured & Total \\
\hline Correct Recall & 9 & 6 & 20 & 9 & 27 & 71 \\
Overt Error & 8 & 1 & 2 & 4 & 6 & 21 \\
Omission & 1 & 21 & 30 & 86 & 54 & 192 \\
$N$ Performances & 18 & 28 & 52 & 99 & 87 & 284 \\
\hline
\end{tabular}


Another interesting pattern is revealed in the recall of the exact date of a performance. The frequencies for date recall and date recall error are presented in Table 4 . The greatest percentage of correctly recalled dates $(50.0 \%)$, given the number of performances, occurred in the first division of performances (performances seen during high school). However, this period also saw the greatest percentage of overt errors $(44.4 \%)$. Other divisions of performances with high percentages of correct date recall (graduate school, $38.5 \%$ correct; tenured, $31.0 \%$ ) show very low percentages of errors. A chi square was calculated using the $3 \times 5$ frequency table in Table 4 . It was highly significant $\left[\chi^{2}(8)=73.205, p<.001\right]$, suggesting that errors in recall of the exact date are not randomly distributed.
Analysis of sequential order and recall order. I chose to start free recall with the first season (1962-1963) and work upwards sequentially through the seasons to the present. When I hit a snag in the 19th season (1980-1981), I jumped ahead to the final season, which was still fresh in mind, and worked backwards through the seasons.

The relationship between real performance order and recall order is best illustrated in the performance plot of Figure 1. The correlation between real performance order and recall order was positive and highly significant $[r(200)$ $=.834, p<.01]$; this fact can be gleaned immediately upon inspection of the figure. Also immediate is the observation that the seasons differ in the degree to which the sequential order of recall is in line with the real sequence of performances. The early seasons show only

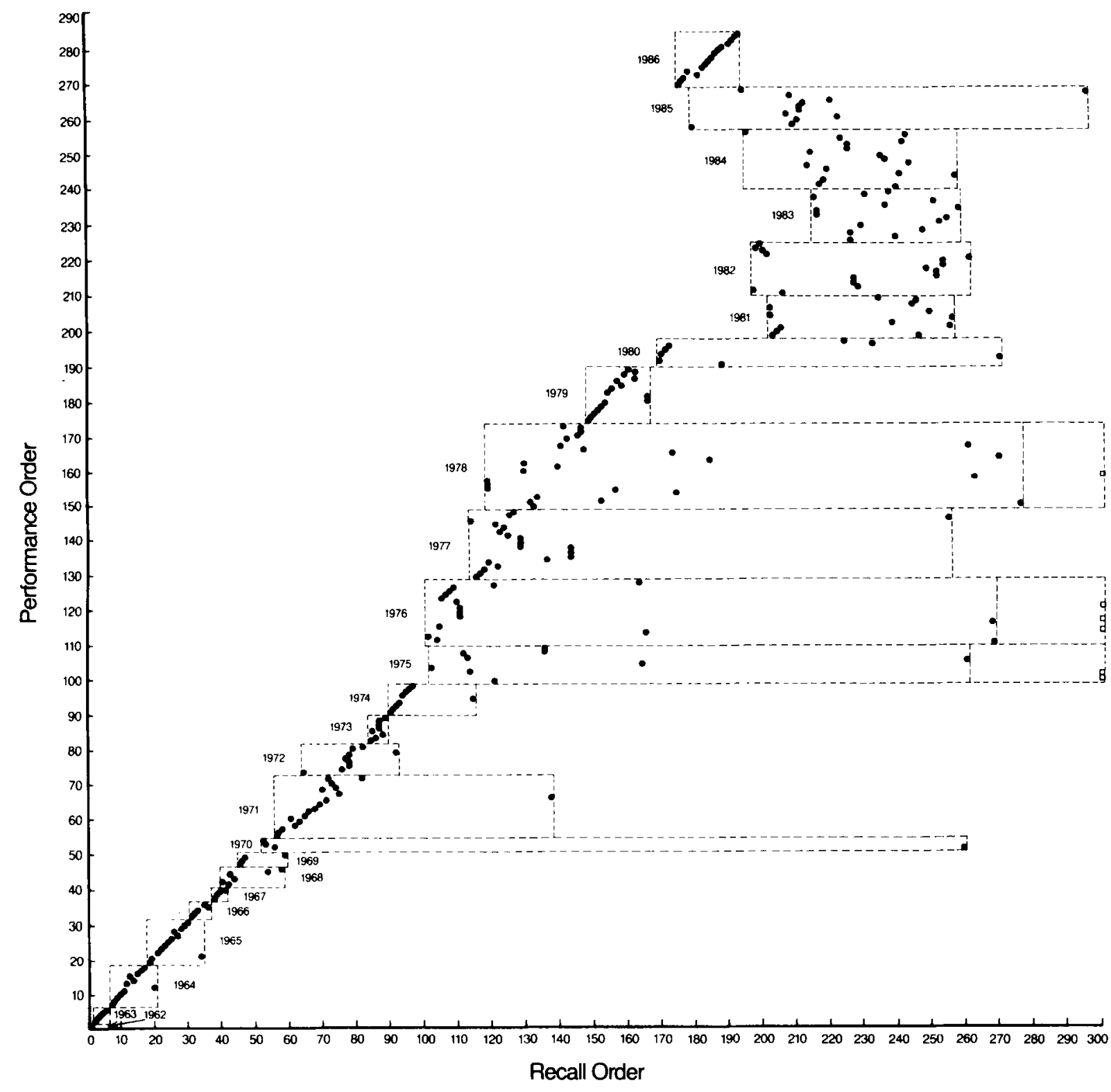

Figure 1. Recall order of performances as a function of real performance order. Each point represents one performance; each box represents one season. Six open squares represent six performances omitted from recall. 
minor deviations from perfect sequential recall; the later seasons, particularly the 1976-1977 and 1978-1979 seasons, show marked deviations from the sequential order. Again, given that I consciously chose a sequential recall strategy, it is not remarkable that recall order is related to the real performance order. What is remarkable, however, is that certain seasons defied this strategy, suggesting that temporal structure or temporal schemata, or merely the sequential order within these seasons, is weak or nonexistent.

Analysis of sequential variance and correct recall. If one assumes that the difference between recall order and the real sequential order represents a weakening of temporal structure for that unit of memory, then the recall of temporal features for that performance would be expected to be less than the recall of temporal features for performances that are recalled within the sequential order of performances of a season. Unattached to a season's sequential string, these performances would have to be generated from other cues. Though the information necessary to reconstruct their positions in the sequence may be available, it also may be missing completely. In addition, it would not be surprising to find that recall of casting is somehow related to a performance's place in the recall sequence.

Thus, two analyses of sequential structure were developed. The first took each season as a unit and assessed the degree to which the real performance order within the season was matched by recall order of performances within the season. The second took each performance as a unit and assessed the degree to which its recall order differed from its real performance order. Both analyses, ultimately spatial in nature, represent the memory for the group of performances within a season or the memory for a single performance as a deviation from that group's or performance's expected place in the sequential order.

The analysis of sequential structure by seasons was developed according to the following logic: With reference to Figure 1, it will be noted that recalling each performance within a given season in perfect sequential order results in a straight diagonal rising one step at a time from the lower left corner of a dashed line square (the season area) to the upper right corner. The area of the square transected by this diagonal can be found simply by squaring the number of performances within the season. The second season (1963-1964), a case in which the recall sequence perfectly matched the real performance sequence of that season, illustrates the diagonal and a square season area. But the recall of performances in other seasons shows radical departures from the real performance sequence and, in all but a few seasons, the effect of a deviation from the real performance sequence is to widen the season area into a rectangle. The "recall width" of a season was found by subtracting the lowest recall order position of a performance within the season from the highest recall order position and adding 1 . A value called the sequential sum of squares was calculated by subtracting the expected area of a season (number of performances squared) from the observed area of that season (number of performances $x$ recall width). A quantitative variable called sequential variance was calculated by dividing the sequential sum of squares by the number of performances in a season. An inspection of Figure 1 will verify that the sequential variance of the 25 seasons ranges from a low of 0 (the 1st and 2nd seasons) to a high of 205 (for the 1970-1971 season).

Is the sequential variance for a season related to differences in recall of performances within that season? If sequential variance reflects a breakdown in the schematic structure, then most likely the amount of correct recall for performances within that season will be negatively correlated with sequential variance. And this was in fact found: The mean correct recall of temporal features of performances within a season was negatively and significantly correlated with sequential variance $[r(23)=$ $-.636, p<.01]$, as was the mean correct recall for casting $[r(23)=-.552, p<.01]$. Thus, the sequential variance, a measure constructed to reflect disturbances of recall sequence within a season, is related to other deficits in recall.

Do these relationships hold when individual performances are analyzed? The performance sequential variance was calculated by subtracting the sequential order of each performance from the recall order of the performance. If the performance was recalled after its real place in the sequence, this calculation resulted in a positive value; if the performance was recalled before its appointed place, this calculation resulted in a negative value. Scores of the variable performance sequential variance ranged from -94 (for the performance of Bellini's I Puritani from 1986-1987) to a high of 209 (for the performance of Verdi's Ernani, which started the 1970-1971 season). The mean of performance sequential variance for all performances was -.736 .

Following the logic above, performances recalled after their places in the sequence (positive values for performance sequential variance) may be stragglers left behind as recall proceeds along a temporal sequence. Perhaps the memory representations for these performances are, in general, weaker, less clear, or less detailed. Conversely, it is possible that the performances recalled ahead of their places in the sequence (negative performance sequential variances) came quickly to mind because of their relative strengths in memory. Relative strength in memory should include, one hypothesizes, more details, more correct recall, and so on.

With stronger memories receiving negative scores and weaker memories receiving positive scores on this measure of sequential variance, negative correlations were expected between this variable and the measures of correct recall for features of the performances. As predicted, the relationships between performance sequential variance and correct recall of temporal features and correct recall of casting were negative and significant $[r(200)=-.525$ 
and $-.367, p<.01]$. A check on the relationships between performance sequential variance and specific temporal features shows a consistently significant set of correlations that range from -.572 (for correct recall of the opera) to -.296 (for correct recall of the season). This last correlation is low because, as reported above, correct recall of seasons was most often the case.

\section{Discussion}

Four important findings emerge from Experiment 1. First, the classic primacy/recency curve was found in the exhaustive free recall of this serial list in very long-term autobiographical memory. That there should be a pronounced recency effect is not surprising: the final season (1986-1987) was still fresh in memory when I attempted recall. The relatively straight diagonal for this season in Figure 1 shows that the season exists, at least for the time being, as an intact chunk in memory.

The primacy effect for items originally learned over 25 years ago may be explained by a variety of mechanisms. Crowder (1976) suggested that the distinctiveness of primacy items accounts for their superior recall. The early operas on my list are certainly distinct, not just by virtue of their being first. Thirty-three performances (4 seasons) were at the original Metropolitan Opera House on Broadway and 39th Street. And many of the artists whom I saw in those first performances were already stars of international stature (e.g., Maria Callas, Renata Tebaldi, Tito Gobbi, Elisabeth Schwarzkopf, etc.).

These singers were also featured on most of the major opera recordings and in most of the photograph books I purchased during that era. Listening to these recordings and leafing through the books served as a rehearsal of memories of the early performances. It is possible too that details of the early performances became overlearned through countless repetitions in conversations with friends and acquaintances. The almost perfect linear sequence of recall in Figure 1 suggests the permanence of these early memories.

The distinctiveness/rehearsal/overlearning explanation also accounts for the von Restorff effect for recall of operas in the 1979-1980 season (see Figure 1). This season stands out in my memory as the first one my wife and $I$ attended together. We frequently reminisce about those years and, consequently, rehearse and consolidate our remembrances. Thus, though the primacy/recency effect was observed in my recall of 25 years of autobiographical facts, it is likely that the primacy effect was due at least in part to the circumstances surrounding the first operas that were specific to my life. The primacy effect may be absent in another person's recall of another longterm list of autobiographical facts. On the other hand, the recency effect, one suspects, is a more generalizable finding.

A second finding to emerge from Experiment 1 is that the influence of larger temporal chunks is reflected in my recall of opera performances. I chose to recall performance details by opera season, and so it is quite under- standable that the opera season appears to be a meaningful temporal chunk in my memory. My recall strategy was chosen because it seemed the most orderly way to go about recalling a list of so many items.

The pattern of recall presented in Figure 1 suggests that, for the most part, the boundaries of these season chunks are well formed and psychologically real. A comparison of the dispersion in recall within the 1978-1979 season with that within the following season (1979-1980) shows that even adjacent seasons differ widely in cohesion. On a broader scale, the analysis of the larger, more personally meaningful temporal chunks of my career illustrates the hierarchical temporal reference systems described by Robinson (1986) and Neisser (1986).

The third finding is that the size of the deviation of recall sequence from the real performance sequence, either measured on the aggregate level of the opera season or on the level of individual performance, may provide another indication of the strength of the representation in memory of the experience of an opera performance. Or, it may suggest that retrieval suffers where there is a breakdown of the organization of the temporal reference system (Robinson, 1986).

The fourth finding to emerge from Experiment 1 is that recall accuracy varied according to the language of the opera, the day of the week of the performance, the time of the performance (matinee or evening), and the production status (new production or revival). These details in themselves may have aided recall by providing additional retrieval cues, or they may have simply been extra details accompanying the more pleasant memories (Thompson, 1985). Another possibility is that the Metropolitan Opera tends to present better casts for the German operas, on Mondays and Saturdays, for matinee performances, and in new productions. Better casts usually mean more intense, more emotional experiences at the opera and, therefore, following Rubin and Kozin (1984), mean more vivid memories.

\section{EXPERIMENT 2}

More intense, more significant events are retained in autobiographical memory more than are less intense, less important events. How can the intensity of an experience be estimated in retrospect without the circularity of availability ("It must have been intense because I remembered it."')? In Experiment 2, it is assumed that the more intense and noteworthy operatic experiences have been captured in the various media. The appearance of a singer, for example, on a recording suggests that the singer is important enough to be recorded. And it follows that my experience of this singer on stage was probably more intense than my experience of some other singer who is less well known and not recorded. An objective match between the cast of an opera performance in my past and the cast of a recording in my collection is here considered an estimate of the intensity or importance of that performance. Are more intense, more important performances better 
remembered in my free recall of details of 284 opera performances? Nine estimators of performance intensity were constructed to answer this question.

The various media also provide excellent opportunities for rehearsal of performance details over the years. Each time I play a recording or leaf through a book of photographs about the Metropolitan Opera, I conjure images and emotions from performances past. The nine estimators of performance intensity, then, must also be considered estimators of rehearsal opportunity and memory maintenance. ${ }^{4}$

\section{Method}

Selection of nine estimators of performance intensity/rehearsal opportunity. Nine estimators of performance intensity/rehearsal opportunity were chosen according to the following criteria. First, the estimator must be a public document, such as a book, a recording, a telecast, or a catalogue. It must be or have been available to everyone. Second, the recording or telecast must have been assembled by some person or persons highly knowledgeable in the field of opera. Third, the book, catalogue, recording, or video must have been in my collection of books, catalogues, and recordings ${ }^{5}$ for at least a year and must have been easily accessible during that time. Fourth and finally, estimators of performance intensity/rehearsal opportunity must be based on simple and objective counts.

The nine estimators were:

1. The number of performers (singers and conductors) in each performance I saw at the Metropolitan Opera represented in any commercial or noncommercial recordings in my collection. Approximately 375 complete and excerpted performances of operas were used for this estimator.

2. The number of performers in each performance I saw at the Metropolitan Opera represented on commercial recordings in my collection in the exact same role as in the performance on stage. One hundred forty-six recordings were relevant to the 94 operas in the recall sample. There was at least 1 recording of 82 of the operas, and there were 2 different recordings of 41 of the operas. At the upper end, there were 5 different recordings and tapes of two operas (Wagner's Parsifal and Puccini's Tosca). More than Estimator 1, this estimator was an excellent opportunity for rehearsal of the memory of a performance. In some cases in which the commercial recording was made around the time of a performance or the recording was a private tape of a Metropolitan Opera broadcast, the match in casts was nearly identical.

3. The number of performers in each performance I saw represented on a special 100th season commemorative set of recordings. The Metropolitan Opera Guild issued eight two-record volumes in a series entitled One Hundred Years of Great Artists at the Met. Five volumes of the One Hundred Years of Great Artists at the Met series were relevant as sources for this estimator: The Johnson Years (1935-1950), The Bing Years I (1950-1961), The Bing Years II (1961-1972), Completing the Century (1972-1983), and The Conductors (1883-1983).

4. The number of performers in each performance I saw represented in the One Hundred Years of Great Artists at the Met series singing the exact same role as the role in which I saw them on stage.

5. If a telecast was identical to a performance I saw on the stage of the Metropolitan Opera, then that performance received a 1, otherwise 0 .

6. The number of performers in each performance I saw represented in the underground tapes of performances of the same opera from the opera stages in other parts of the world. The Live Opera Tape Catalogue from 1978 (with addenda from September 1979 to September 1985) was scanned for entries under the 94 operas
I have seen; cast members were matched. It was assumed that the individual who assembled this catalogue chose to include mainly intense, important, historically valuable (and marketable) performances here.

7. The number of performers in each performance I saw represented in Celebration: The Metropolitan Opera, written by the late Francis Robinson and published in 1979. Only artists depicted in this book as portraying the same roles as they did in performances I saw at the Metropolitan Opera were counted.

8 The number of performers in each performance I saw represented in The Golden Horseshoe: The life and Times of the Metropolitan Opera House, published in 1965 during the final season of the old Metropolitan Opera House on Broadway and 39th. Again, the artist had to have been pictured in the exact role and production in which I saw him or her in a performance at the Metropoli$\tan$ Opera

9. The number of performers in each performance I saw represented in any of eight Metropolitan Opera Guild engagement calendars from the years 1969, 1970, 1972, 1973, 1975, 1977, 1982, and 1983. Here too, I required that the artist be pictured in the exact role and production in which I saw him or her in a performance at the Metropolitan Opera

In sum, nine estimators were drawn from reasonably public sources. These nine not only estimate the intensity or importance of performances but also estimate the degree to which I may have rehearsed the details of performances over the years.

\section{Results}

Scoring. The cast of each of the 284 performances was compared with the nine estimators of performance prestige; counts of the numbers of matches were entered into the data file.

Correlation analysis. The nine estimators of performance intensity/rehearsal opportunity should at least be positively correlated with correct recall of casting information and temporal features, because, as argued above, as the importance of the performance increases, thus making it more memorable, and as the opportunities to rehearse and maintain details of the performance in memory increase, so too should the accuracy of recall increase.

The results of the correlation analysis are presented in Table 5 .

The first and most general finding is that there were significant relationships between correct recall of casting and estimators of performance intensity/rehearsal opportunity. The correlations suggest simply that a more intense and important performance is more memorable and probably better rehearsed in memory over the years. The significant relationships between the nine estimators and casting recall are perfectly understandable in that the estimators were drawn from counts of recording casts or photographs of artists.

Some estimators were better predictors than others. The correlations between correct recall of casting and matches of general casting from the recordings in my collection (Estimator 1) and between correct recall of casting and matches of general casting from the recordings in the series One Hundred Years of Great Artists at the Met (Estimator 3) show that the general estimators are more effective than are their more tightly constrained variants (Estimators 2 and 4). 
Table 5

Correlation Matrix for Nine Estimators of

Performance Prestige and Two Recall Variables

\begin{tabular}{cccccccccc}
\hline & \multicolumn{7}{c}{ Estimator } \\
\cline { 2 - 10 } Estimator & 1 & 2 & 3 & 4 & 5 & 6 & 7 & 8 & 9 \\
\hline 2 & $.325 \dagger$ & & & & & & & & \\
3 & $.598 \dagger$ & $.232 \dagger$ & & & & & & & \\
4 & $.250 \dagger$ & $.417 \dagger$ & $.312 \dagger$ & & & & & & \\
5 & .132 & .005 & $.255 \dagger$ & -.039 & & & & & \\
6 & $.468 \dagger$ & $.365 \dagger$ & $.393 \dagger$ & $.424 \dagger$ & .085 & & & & \\
7 & $.206 \dagger$ & .114 & $.281 \dagger$ & $.221 \dagger$ & .007 & $.208 \dagger$ & & & \\
8 & $.143 *$ & $.202 \dagger$ & .048 & -.033 & .038 & .116 & -.036 & & \\
9 & $.285 \dagger$ & $.219 \dagger$ & $.255 \dagger$ & .074 & $.388 \dagger$ & $.241 \dagger$ & $.162 *$ & .042 & \\
10 & .049 & .078 & -.067 & -.012 & .085 & .047 & $-.139^{*}$ & .022 & .043 \\
11 & $.381 \dagger$ & .104 & $.257 \dagger$ & .060 & $.241 \dagger$ & $.209 \dagger$ & .103 & $.148^{*}$ & $.230 \dagger$ \\
\hline
\end{tabular}

Note-Variables were as follows:

1. Performer match from recordings in collection.

2. Performer/role match from recordings in collection.

3. Performer match from One Hundred Years of Great Artists at the Met series.

4. Performer/role match from One Hundred Years of Great Artists at the Met series.

5. Telecast in Live from the Met series.

6. Performer/role match from private tape catalogue.

7. Performer/role match from Celebration.

8. Performer/role match from The Golden Horseshoe.

9. Performer/role match from eight Metropolitan Guild engagement calendars.

10. Temporal recall.

11. Casting recall.

${ }^{*} p<.05 . \quad \dagger p<.01 . \quad d f=200$.

None of the nine estimators of performance intensity/rehearsal opportunity was correlated both significantly and in the right direction with correct recall of temporal features. The nine sources were ineffective as aids to recall of details of a performance's place in time. This finding is not completely surprising: If a production is shown in a book that has a publication date of 1979 , then, without reading the fine print, one can conclude only that a performance happened before 1979; likewise, an artist may make a recording many years before or after his or her performance of the role at the Metropolitan Opera.

Other observations may be drawn from the intercorrelations among the nine estimators. Many of the artists who are featured on recordings in my collection (Estimator 1) were also selected by the Metropolitan Opera Guild for the One Hundred Years of Great Artists at the Met series $(r=.598)$ and have appeared in privately taped performances around the world $(r=.468)$. The relationships hold even when the match between my collection and the Metropolitan Opera Guild's series is constrained to exact role $(r=.417)$. These artists also tended to be pictured in the three photograph estimators, which shows, simply, that the top artists in the field of opera turn up in most media. The low intercorrelations among the three photograph estimators may stem from the fact that these sources span different periods in the past 25 years at the Met.

More interesting findings emerge when the nine estimators are correlated with some of the variables mentioned in Experiment 1. It was suggested, for instance, that the cast of an opera performance was better remembered if the opera was sung in German. The significant correlations between Estimators 1 and 2 and German lan- guage ( $r=.257 ; r=.180$ ) suggest that the artists who are cast in these performances are more likely to be of international stature (and, thus, more likely to appear on commercial recordings that, for the most part, are cast and recorded in Europe). It may also be that I selected recordings for my collection because of the overlap between artists in the recordings and the artists whom I saw on stage. Weight to the selection argument is added by inspecting Estimators 3 and 4. Here, where the Metropolitan Opera Guild chose the artists and selections, significant relationships appeared with artists in performance if the opera was sung in Italian $(r=.255 ; r=.197)$. Telecast (Estimator 5) correlated . 175 with Italian language, but -.147 with German, indicating that the majority of the Metropolitan Opera telecasts have been Italian operas.

Four of the estimators correlated with the production status of a performance. Artists featured on recordings in my collection tended to appear in new productions $(r=.170)$, as did those featured in the One Hundred Years of Great Artists at the Met series $(r=.177)$, those pictured in Celebration (Estimator $7 ; r=.455$ ), and those pictured in the eight engagement calendars $(r=.345)$.

\section{EXPERIMENT 3}

A better estimate of the intensity of a performance is a rating by an opera expert who is familiar with the repertory and quality of the performances at the Metropolitan Opera. In Experiment 3, four experts rated each of the 284 opera performances on my list to the degree that the performance was intense and memorable. In a second task, they then compared all the performances of each 
opera and rank ordered them according to their intensities. The two ratings were combined to give a fair estimation of a performance's intensity.

Once again, however, there is a confound between intensity and opportunity for rehearsal. Discussions of opera and experiences usually revolve around the intense and memorable performances; the same people with whom I have discussed musical matters are the opera experts in this experiment. Many of us attended the same performances, listened to the same recordings, and watched the same videos. Thus, each discussion serves as a chance to rehearse details of past performances. Each rating, then, can be considered not only a rating of a performance's intensity but also a rating of the performance's chances of coming up in conversations among experts.

\section{Method}

Subjects. Five friends were asked to participate in the rating and ranking tasks reported below. Only four completed the task. Each was chosen because each has had much experience with the world of opera and has access to a large collection of recordings and publications. Their experiences of the Metropolitan Opera performances cover a considerable range: 1 expert saw his first opera in 1957 and has been a regular subscriber to the Metropolitan Opera since the 1959-1960 season. He has attended more performances than I and the other 3 raters combined. At the other extreme, 1 attended his first opera at the Met in the fall of 1977 , quickly reached a peak number of performances per season (1978-1979), and then settled into regular but less frequent attendance. Though the 4 raters volunteered for the tasks, each was paid $\$ 20.00$ for participating.

Rating materials and scales. A total of nine tasks were constructed; the details and results of two are reported below. A task booklet of the nine tasks, instructions, and lists was assembled. For the two tasks of interest here, the 284 opera performances were each listed with conductor and at least three major cast members. The information for this listing was taken directly from the master scoring sheet used in Experiment 1. However, the chronological order of performances was broken down and completely altered: here, opera performances were grouped in clusters according to opera; within each opera cluster, performances were randomly ordered; any indications of the date or season of a performance, other than that which could be deduced from the cast listing, were eliminated. Any repeat performances of an opera, in which cast and conductor were identical, were removed from a cluster. The total number of unique performances on this list was 261 .

In the first rating task, the subjects were asked to rate each opera performance from 5 (most intense, most memorable) to 1 (less intense, less memorable). Constraints were set to force variability in ratings: each number had to be used at least 15 times but no more often than 75 times. In the second task, the subjects were asked to rank each performance within a cluster of performances of the same opera from 1 to $N$ (most intense or memorable to least intense), where $N$ was defined as the number of performances within the cluster. Thus, for Die Meistersinger von Nümberg, with a cluster size of eight performances, subjects ranked the most intense or most memorable performance of this opera as a 1 and the least intense performance as an 8 .

As stated above, the two tasks were embedded in a total set of nine rating, ranking, memory, and estimation tasks. The nine tasks concerned opera in general and the Metropolitan Opera in specific. The results of the other seven may be reported elsewhere.

Instructions. Experts were told to rate opera performances in light of their characteristics, "on paper."

Procedure. The rating booklets were distributed in late October, 1987. All 5 subjects were aware of my project in advance of the tasks. The instructions explicitly referred to the objective of rating performances without trying to guess the status of the performance in my memory. In addition, before and during the rating period, we refrained from any discussions or comparisons of their ratings and from any discussions that compared current performances with any from previous seasons. The rating booklets were collected in the 3rd week of November, 1987

\section{Results}

The four sets of ratings and rankings were entered into the data file. The 23 performances not listed in rating list of 261 performances were given the values of their identical counterparts. Thus, each of the 284 performances received ratings and rankings by the 4 raters.

In the first task, a high rating indicated that a performance was very intense or memorable, whereas a low rating indicated that a performance was not particularly memorable. A positive correlation between these ratings and the degree to which I was able to recall details of a performance, then, suggests that there is some quality of a performance, perceived by myself and by others, that affects storage and recall of the performance.

All correlations between rating and my recall of casting information were both positive and significant at the .01 level. The mean correlation was .287 . The highest correlation between ratings and my recall comes from the rater with the most experience of the Metropolitan Opera $(r=.357)$, while the lowest correlation comes from the rater with the least $(r=.181)$.

In contrast, though all of the correlations between rating and my recall of temporal information were positive, none was close to the level of significance

Raters differed somewhat in their perceptions of a memorable performance: intercorrelations among raters ranged from .473 to .308 .

The mean rating was calculated for each performance. Five groups were formed with the following cutpoints: the first group was composed of 36 performances rated as least memorable (mean rating less than 2.7); the second group (52 performances) had a mean rating greater than or equal to 2.7 but less than 3.2 ; the third group ( 71 performances) had a mean rating greater than or equal to 3.2 but less than 4.0 ; the fourth group (70 performances) had a mean rating greater than or equal to 4.0 but less than 4.5 ; and, finally, the fifth group, the group of 55 most memorable performances, had a mean rating of greater than or equal to 4.5. A one-way analysis of variance shows that grouping performances in this manner accounts for a significant portion of the variance of correct recall of casting information $[F(4,279)=11.21$, $p<.01]$. The mean correct recall of casting for the five groups is presented in Table 6.

In contrast, this grouping revealed no effect for the recall of temporal information $[F(4,279)=2.32$, n.s.].

In general, the results of the second task, the ranking of performances by intensity within a cluster of performances of the same opera, were similar to those reported above. Unfortunately, the design of the experiment precludes a simple summary. The subjects were asked to 
Table 6

Mean Correct Recall

for Casting for Five Groupings of Mean Rankings

\begin{tabular}{lccccc}
\hline & \multicolumn{5}{c}{ Mean Rating of Performance Prestige } \\
\cline { 2 - 6 } & $<2.7$ & $2.7-3.2$ & $3.2-4.0$ & $4.0-4.5$ & $>4.5$ \\
\hline $\begin{array}{l}\text { Mean correct recall } \\
\text { for casting }\end{array}$ & 3.028 & 3.865 & 4.620 & 4.500 & 5.145 \\
$N$ Performances & 36 & 52 & 71 & 70 & 55 \\
\hline
\end{tabular}

Note-High rating $=5$.

rank performances from 1 to $N$, where 1 was considered most memorable and $N$ least memorable. But in the case of an opera with only a single performance, the value of a 1 was assigned automatically, regardless of the quality of that performance, while in the case of an opera with nine performances, a 1 represented the best out of nine! Thus, it would be unwise to collapse over ratings of differently sized clusters.

The decision was made to treat this ranking task as nine separate miniexperiments. In effect, subjects were asked to rank opera performances in clusters of single performances in the first miniexperiment, then to rank performances in clusters of two performances of the same opera in the second miniexperiment, then to rank performances in clusters of three performances of the same opera, and so on to a final ranking of the performances in clusters of nine performances of the same opera. Since subjects automatically assigned a 1 to single-performance clusters, there was no real ranking task in the first miniexperiment. A total of 28 performances fell into this category.

In the eight analyses that follow, two methods were chosen to collapse over subjects. In Table 7, the first and second columns present the mean correlations calculated from the four correlations between a recall variable (casting or temporal) and the rankings of the 4 subjects. The third and fourth columns of Table 7 present correlations in which a mean ranking for 4 subjects was calculated

Table 7

Mean Correlations for Nine Miniexperiments Ranking Opera Clusters

\begin{tabular}{ccccccc}
\hline $\begin{array}{c}N \text { Operas } \\
\text { in Cluster }\end{array}$ & 1 & 2 & 3 & 4 & 5 & 6 \\
\hline 2 & -.120 & -.123 & -.177 & -.181 & -.541 & 55 \\
3 & -.288 & -.057 & -.371 & -.074 & -.702 & 53 \\
4 & -.164 & -.214 & -.190 & -.249 & -.740 & 30 \\
5 & -.474 & -.373 & -.596 & -.470 & -.608 & 21 \\
6 & -.249 & .196 & -.293 & .234 & -.810 & 36 \\
7 & -.522 & -.264 & -.563 & -.285 & -.926 & 14 \\
8 & -.363 & -.336 & -.428 & -.394 & -.900 & 17 \\
9 & -.236 & -.067 & -.293 & -.082 & -.883 & 30 \\
\hline
\end{tabular}

Column 1: Mean correlation between ranking and recall of casting information.

Column 2: Mean correlation between ranking and recall of temporal information.

Column 3: Correlation between mean ranking and recall of casting information.

Column 4: Correlation between mean ranking and recall of temporal information.

Column 5: Correlation between rankings and ratings from Task 1.

Column 6: Number of performances included in ranking. first and used in the correlation between ranking and a recall variable.

In the eight ranking tasks, smaller numbers indicated greater intensity of a performance and larger numbers indicated lesser intensity. Thus, if intensity of a performance is related to greater recall, one should expect negative correlations between ranking and correct recall.

A cumulative assessment of these findings can be made by calculating a weighted mean correlation coefficient (Hunter, Schmidt, \& Jackson, 1982). The weighted mean correlation for mean rankings and correct recall of casting information over the eight miniexperiments reported here was -.321 ; the weighted mean correlation for mean rankings and correct recall of temporal information was -.140 .

A crude but simple way to combine the scales from both tasks is to divide a performance's rating (Task 1) by its ranking (Task 2). A performance rated 5 and ranked 1 would still receive the value of 5 , whereas a performance rated 5 but ranked 2 would get an "adjusted" value of 2.5. When the case in which the first ranked performance was rated 4 and the second ranked performance was rated 4 is compared to the case in which first and second ranks are each rated 5 , the sequence of adjusted values $(5,4$, $2.5,2$ ) better reflects the flavor of the rating and ranking scales. The new variable was called adjusted ranking. Since the division of rating by ranking yields a positively skewed distribution, it was decided to take a logarithmic transformation of the adjusted ranking.

With the variable log adjusted ranking, the more intense, more memorable performances received high positive scores and the less intense performances received lower positive and (because of the logarithms) negative scores. Positive correlations were expected between log adjusted ranking and degree of correct recall. Once again, correlations were calculated within the confines of the eight miniexperiments.

Correlations between log adjusted ranking and correct recall of casting ranged between .637 and .253 over the eight miniexperiments. The weighted mean correlation here was .395. And the correlations between log adjusted ranking and correct recall of temporal information ranged between .395 and -.199 ; the weighted mean correlation was .116.

The ratings of performance intensity from this experiment correlate with the nine estimators of performance intensity from Experiment 2 . The mean rating over 4 subjects correlated positively and highly with seven of the 
nine estimators $(p<.01, d f=200)$. Correlations ranged from .460 (between mean rating and intensity estimation based on casts of recordings in my collection; Estimator 1) to .258 (between mean rating and the estimation based on the Metropolitan Opera Guild engagement calendars; Estimator 9). The correlations between mean rating and the remaining two estimators (telecasts, Estimator 5, and The Golden Horseshoe, Estimator 8) were also positive and significant $(p<.05)$, but lower $(r=.145$ and .147 , respectively). The German operas were rated higher than the non-German operas $[r(200)=.156, p<.05]$, as were the casts of the new productions $(r=.134)$.

\section{SUMMARY ANALYSES OF THE EXPERIMENTS}

Several variables from the three experiments have been shown to be significant predictors of my recall of casting and temporal details of 284 performances at the Metropoli$\tan$ Opera. They represent different aspects of the recall process. It is useful to combine the best predictors of recall performance through multiple regression analysis and assess their relative weights in the overall picture.

Six predictors were selected from the three experiments. The first predictor of recall performance was the serial position in time of the actual performance. The classic primacy and recency effects were found in Experiment 1 for recall of both casting and temporal details. Rather than try to combine polynomial regression and multiple linear regression in the summary analysis, it was decided to adopt a different strategy: to use instead the predicted value of amount of recall as a function of $\log$ serial posi- tion (calculated from the polynomial regression equations in Experiment 1). Then the simple correlation between observed amount of recall and this predicted amount would reflect the contribution of the polynomial serial position analysis.

The second predictor was performance sequential variance in Experiment 1. It was calculated by subtracting the real sequential order from the recall order for each performance. A performance recalled on or before its expected order is, it was assumed, represented in memory more vividly, whereas the performance recalled long after its appointed location in the real performance sequence reflects some weakness in the representation of the performance in the structure of autobiographical memory. Performance sequential variance, then, was taken to represent the strength of the representation within the mnemonic order.

The third predictor variable was the first estimator from the nine estimators of performance intensity in Experiment 2. How many performers in a performance I saw at the Metropolitan Opera were represented on a commercial or private recording in my collection? This estimator yielded the highest correlation with recall among the nine estimators.

The fourth predictor variable was the fifth of the nine estimators of performance intensity in Experiment 2: Was the performance telecast in the Live from the Met series on PBS during the past 11 years?

The fifth predictor was constructed by summing the counts from the three estimators drawn from photographic sources. The combination was justified in that the three sources cover different eras within the 25 -season span.

Table 8

Correlation Matrix for Six Predictors and Three Dependent Variables (Temporal Recall, Casting Recall, and Total Correct Recall)

\begin{tabular}{ccccccccr}
\hline & 1 & 2 & 3 & 4 & 5 & 6 & 7 & 8 \\
\hline 2 & .132 & & & & & & & \\
3 & -.080 & -.026 & & & & & & \\
4 & $.145^{*}$ & $.460 \dagger$ & -.058 & & & & & \\
5 & $.297 \dagger$ & $.350 \dagger$ & .048 & $.383 \dagger$ & & & & \\
6 & -.043 & .011 & $-.449 \dagger$ & -.027 & $-.182 \dagger$ & & & \\
7 & .064 & -.049 & $-.387 \dagger$ & -.037 & $-.224 \dagger$ & & & \\
8 & -.004 & -.025 & $-.436 \dagger$ & -.056 & $-.230 \dagger$ & & & \\
9 & .085 & .049 & $-.525 \dagger$ & .074 & -.038 & $.444 \dagger$ & & \\
10 & $.241 \dagger$ & $.381 \dagger$ & $-.367 \dagger$ & $.370 \dagger$ & $.256 \dagger$ & & $.335 \dagger$ & \\
11 & $.210 \dagger$ & $.289 \dagger$ & $-.520 \dagger$ & $.294 \dagger$ & $.158^{*}$ & & & $.431 \dagger$ \\
\hline
\end{tabular}

Note-Predictor variables included

1. Telecast in Live from the Met series.

2. Performer match from recordings in collections

3. Performance sequential variance.

4. Mean performance prestige rating.

5. Performer/role match combined over three photograph sources

Serial position variables included:

6. Predicted value for temporal recall.

7. Predicted value for casting recall.

8. Predicted value for total correct recall. Dependent variables included:

9. Temporal recall.

10. Casting recall

11. Correct recall

${ }^{*} p<.05 . \quad \dagger p<.01 . d f=200$ 
The third, fourth, and fifth predictors reflect a combination of rehearsal opportunities from the various media as well as an estimation of the importance or intensity of the performances.

The final predictor variable was the mean intensity rating from the 4 raters in Experiment 3 . In addition to providing a rating of performance intensity, this predictor probably reflects the frequency with which the memory of a performance is brought up in conversations among friends.

Three dependent variables were analyzed in three separate multiple regression analyses with the six predictors listed above. The three dependent variables were: correct recall of temporal information, correct recall of casting, and total correct recall (formed by adding the amounts of the first two). The total correlation matrix for the three dependent variables and the six predictors is presented in Table 8.

The first multiple regression analysis involved correct recall of temporal information as a dependent variable. The analysis of variance for the regression of the six predictors is highly significant $[F(6,277)=23.401, p<$ $.01]$. The $R^{2}$ was .336 . An analysis of the regression coefficients suggests, however, that only serial position and performance sequential variance are significant predictors for this dependent variable. The intercept, coefficients, and standard errors are presented in Table 9.

The second multiple regression analysis involved correct recall of casting as a dependent variable. Again, the analysis of variance for the regression of the six predictors is highly significant $[F(6,277)=31.482, p<.01]$. The $R^{2}$ was .405 . An analysis of the regression coeffi-

Table 9

Regression Coefficients and Intercept for Multiple Regression Analysis of Temporal Recall and Six Predictor Variables

\begin{tabular}{lcccc}
\hline \multicolumn{1}{c}{ Variables } & Coefficient & $S E$ & $T$ & $p$ \\
\hline Telecast & .2247 & .1973 & 1.14 & n.s. \\
Recordings & .0082 & .0551 & .15 & n.s. \\
Sequential & -.0107 & .0015 & -7.18 & .01 \\
$\begin{array}{l}\text { Mean prestige } \\
\quad \text { rating }\end{array}$ & .0718 & .0841 & .85 & n.s. \\
Photographs & -.0047 & .0307 & -.15 & n.s. \\
$\begin{array}{l}\text { Predicted from } \\
\quad \text { serial position }\end{array}$ & .6015 & .1255 & 4.79 & .01 \\
Intercept & .93223 & & & \\
\hline
\end{tabular}

Table 10

Regression Coefficients and Intercept for Multiple Regression Analysis of Casting Recall and Six Predictor Variables

\begin{tabular}{lcccc}
\hline \multicolumn{1}{c}{ Variables } & Coefficient & $S E$ & $T$ & $p$ \\
\hline Telecast & .5289 & .2572 & 2.06 & .04 \\
Recordings & .3187 & .0713 & 4.47 & .01 \\
Sequential & -.0088 & .0019 & -4.72 & .01 \\
Mean prestige & & & & \\
$\quad$ rating & .3737 & .1090 & 3.43 & .01 \\
Photographs & .1080 & .0403 & 2.68 & .01 \\
$\begin{array}{l}\text { Predicted from } \\
\quad \text { serial position }\end{array}$ & .8591 & .1549 & 5.55 & .01 \\
Intercept & -1.89869 & & & \\
\hline
\end{tabular}

Table 11

Regression Coefficients and Intercept for Multiple Regression Analysis of Total Correct Recall and Six Predictor Variables

\begin{tabular}{lcccc}
\hline \multicolumn{1}{c}{ Variables } & Coefficient & $S E$ & $T$ & $p$ \\
\hline Telecast & .8142 & .3528 & 2.31 & .02 \\
Recordings & .3181 & .0985 & 3.23 & .01 \\
Sequential & -.0196 & .0026 & -7.45 & .01 \\
$\begin{array}{l}\text { Mean prestige } \\
\quad \text { rating }\end{array}$ & .4683 & .1504 & 3.11 & .01 \\
$\begin{array}{l}\text { Photographs } \\
\text { Predicted from } \\
\quad \text { serial position }\end{array}$ & .1006 & .0555 & 1.81 & n.s. \\
\begin{tabular}{l} 
Intercept \\
\hline
\end{tabular} & -.7084 & .1174 & 6.03 & .01 \\
\hline
\end{tabular}

cients shows that not only serial position and performance sequential variance are significant predictors, but also the other four intensity/rehearsal variables. The intercept, coefficients, and standard errors are presented in Table 10.

The third multiple regression involved total correct recall as a dependent variable. The results showed that all variables save the photograph book estimator were significant predictors. The analysis of variance yielded an $F$ of 38.804 , and the $R^{2}$ was .457. The intercept, coefficients, and standard errors are presented in Table 11 .

\section{SUMMARY DISCUSSION}

The results of the summary multiple regression analyses show that although the intensity or importance of a performance and any subsequent rehearsal through recordings, books, telecasts, or conversations may affect the recall of the cast of an opera performance, they have little effect on the recall of temporal information. Only a performance's position in the serial order, specifically primacy or recency, and its location in the recall sequence, which may reflect the strength of the representation in memory, were significantly related to correct recall of temporal structure. Note that both of these variables were related to the recall of casting as well.

What conclusions can be drawn from these data? They suggest that although both the temporal structure and the content of a performance are registered at the time of the experience, the content is more likely to be maintained through rehearsal, retelling, listening, and reading. Left unattended over the years, however, details of an event's place in the temporal structure will quietly decompose.

Some specific dates, such as national and religious holidays, birthdays and anniversaries, are so overlearned and often celebrated that the forgetting of them is rare in the normal population. In my recall, accuracy for specific days and dates was most likely for the distinctive and overlearned series of first performances and for the most recent performances. But as the results of Experiment 1 indicated, it also happened that recall of the exact date was often incorrect for performances at these end points. What may be overlearned and distinctive may not necessarily be accurate. Somewhere over the past 20 or so years the dates of some performances have changed in my memory, 
though, interestingly, without any accompanying changes in the confidence that I knew these dates and could recall them at will. Without information to the contrary, inaccuracies may persist in memory for a lifetime.

In part the loss of specific temporal information in memory reflects our focus in remembering everyday events. We can trade experiences of the same opera with another person even if we have seen different performances at different times. Our focus is on the opera or on our impressions of the opera or on a comparative assessment of the cast of the opera, but our sharing of our experiences usually collapses and discards the detailed time structure of day and date in favor of the more general time structure of the opera season. In everyday conversation, we want to know what happened, where it happened, and who was present; only on occasion is the exact time important. Yes, we may offer a general time structure-such as "in my junior year in high school" or "in one of the last seasons of the old Metropolitan Opera House"-but to say, "my first Götterdämmerung was on December 14, 1963," would seem irrelevantly detailed to any listener.

The data clearly show that some general time structures, such as the opera seasons and the years of my schooling and career, remained functional and intact. More than mere organizational frameworks, these structures (and more public temporal structures) probably aided me in the recall and reconstruction of the remembrances of details of performances during my life. No formal assessment of other possible systems of retrieval cues was made here.

It has been attempted here to estimate the intensity of a performance so as to support the argument that more intense experiences are more vivid in memory and therefore easier to recall. But our understanding of the actual workings of the variable of performance intensity is clouded by a confound: It is not clear if a great performance is remembered well because it is a vivid experience that stamps its impression deeply into the wax of memory, or if it is remembered because there are frequent opportunities to rehearse the memories of great performances through listening, reading, watching, or discussing them. Probably it is because of some combination of both.

The confound is unavoidable, but not uncommon in autobiographical memory research. Consequentiality (see R. Brown \& Kulik, 1977) refers as much to the consequences of remembering the event in conversation as it does to the consequences of the event itself. We often seek another's attention with an offer to relate, from personal experience, "what really happened" at the Callas/ Gobbi/Corelli Tosca in 1965 or at the Vickers/Nilsson Tristan und Isolde in 1974, just as I have often asked older patrons what Flagstad, Melchior, Björling, and Rethberg were really like on stage. We gain importance in the eyes of others (and, consequently, in our own eyes) to the extent that what we can relate is valuable in the social currency.
Thus, what appears to be a troublesome (but unavoidable) confound in my conceptualization of performance intensity may offer an estimation of a broader variable in the storage and maintenance of very long-term autobiographical memories. This broader variable concerns the aspects of our everyday events that form the currency of social interaction. In this currency, information that is more content-centered has a higher denomination than does temporal information, and, though the latter clearly imparts a larger, generalized structure to serially organized subsets of autobiographical memory, it is more often than not thrown off and forgotten like a worn penny.

\section{REFERENCES}

Bahrick, H. P., Bahrick, P. O., \& Wittlinger, R. P. (1975). Fifty years of memory for names and faces: A cross sectional approach Journal of Experimental Psychology: General, 104, 54-75.

Barsalou, L. W., \& SEwell, D. R. (1985). Contrasting the representation of scripts and categories. Journal of Memory \& Language, 24, 646-665

BREWER, W. F. (1986). What is autobiographical memory? In D. Rubin (Ed.), Autobiographical memory (pp. 25-49). New York: Cambridge University Press.

Brown, N. R., Rips, L. J., Shevell, S. K. (1985). The subjective dates of natural events in very-long-term memory. Cognitive Psychology, 17, 139-177.

Brown, R., \& Kulik, J. (1977). Flashbulb memories. Cognition, 5 , 73-99.

Crowder, R. (1976). Principles of leaming and memory. Hillsdale NJ: Erlbaum

Friedman, W. J., \&ilkins, A. J. (1985). Scale effects in memory for the time of events. Memory \& Cognition, 13, 168-175.

Fuhrman, R. W., WYer, R. S. (1988). Event memory: Temporal order judgments of personal life experiences. Journal of Personality \& Social Psychology, 54, 365-384

Hashtroudi, S., Mutter, S. A., Cole, E. A., \& Green, S. K. (1984), Schema consistent and schema inconsistent information: Processing demands. Personality \& Social Psychology Bulletin, 10, 269-279.

Hunter, J. E., Schmidt, F. L., JACkson, G. B. (1982). Metaanalysis: Cumulating research findings across studies. Beverly Hills, CA: Sage.

Kerlinger, F., \& Pedhazur, E. (1973). Multiple regression in be havioral research. New York: Holt, Rinehart and Winston.

Linton, M. (1975). Memory for real-world events. In D. A. Norman \& D. E. Rumelhart (Eds.), Explorations in cognition (pp. 376-404) San Francisco: W. H. Freeman.

Nakamura, G. V., Graesser, A. C. (1985). Memory for scripttypical and script-atypical actions: A reaction time study. Bulletin of the Psychonomic Society, 23, 384-386.

NEISSER, U. (1982). Snapshot or benchmarks? In U. Neisser (Ed.), Memory observed: Remembering in natural contexts (pp. 43-48). San Francisco: W. H. Freeman.

NEISSER, U. (1986). Nested structure in autobiographical memory. In D. Rubin (Ed.), Autobiographical memory (pp. 71-81). New York: Cambridge University Press.

RoBinson, J. A. (1986). Temporal reference systems and autobiographical memory. In D. Rubin (Ed.), Autobiographical memory (pp. 159 188). New York: Cambridge University Press.

Rubin, D. C., KozIN, M. (1984). Vivid memories. Cognition, 16, $81-95$

SChANK, R. C. \& AbELSON, R. P. (1977). Scripts, plans, goals, and understanding. Hillsdale, NJ: Erlbaum.

Simonton, D. K. (1977). Creative productivity, age, and stress: A biographical time-series analysis of ten classical composers. Joumal of Personality \& Social Psychology, 35, 791-804. 
Thompson, C. Р. (1985). Memory for unique personal events: Effects of pleasantness. Motivation \& Emotion, 9, 277-289.

Thompson, C. P., SkowronskI, J. J., \& LeE, D. J. (1988). Reconstructing the date of a personal event. In M. Gruneberg, P. Morris, \& R. Sykes (Eds.), Practical aspects of memory: Current research and issues (Vol. 1, pp. 241-246). Chichester, England: Wiley.

WAGENAAR, W. A. (1986). My memory: A study of autobiographical memory over six years. Cognitive Psychology, 18, 225-252.

\section{NOTES}

1. The set included four performances by the Metropolitan Opera Company that were ouside the obvious criteria: two performances were dress rehearsals at the Metropolitan Opera House, performed by the Metropolitan Opera Company, of operas I saw later in the season. Two others were by the company on their spring tour in Boston, April, 1972.

2. Typically there are four or five major roles in an opera assigned to the five major vocal ranges: soprano, mezzo-soprano, tenor, baritone, and bass. In most cases, the differentiation of a major role from a minor role is obvious. In some cases, however, particularly the operas of the 20th century, the dividing line between major and minor roles is fuzzy. As many names as I thought important and bearing on my recall were taken from programs.

3. Table values for degrees of freedom of 200 were used for deciding the significance levels of correlations.

4. A better estimation would include the frequency with which I listened to the recordings or leafed through the books. But this estimation is circular; it would have to rely on my memory to establish these frequencies.

5. Estimators were not drawn from all possible books on the opera in general, nor even from all possible photograph books I own concerning the Metropolitan Opera in specific. Similarly, estimators were not drawn from every possible recording made or telecast aired, but rather only from the recordings that I own and have listened to or videos I have watched over the years.

(Manuscript received May 17, 1988; revision accepted for publication March 8, 1989.) 